\title{
Corrosion Response of Ti6Al4V and Ti15Mo Dental Implant Alloys in the Presence of Listerine Oral Rinse
}

\author{
Rahul Bhola, ${ }^{1}$ Charu Chandra, ${ }^{2}$ Faisal M. Alabbas, ${ }^{1,3}$ Sukumar Kundu, ${ }^{1,4}$ \\ Brajendra Mishra, ${ }^{1}$ and David L. Olson ${ }^{1}$ \\ ${ }^{1}$ Department of Metallurgical and Materials Engineering, Colorado School of Mines, Golden, CO 80401, USA \\ ${ }^{2}$ Department of Chemistry, University of Delhi, Delhi 110007, India \\ ${ }^{3}$ Department of Inspection, Saudi Aramco, Dhahran 31311, Saudi Arabia \\ ${ }^{4}$ Department of Metallurgy and Materials Engineering, Bengal Engineering and Science University, Shibpur, Howrah 711103, India
}

Correspondence should be addressed to Rahul Bhola; bhola.rahul@gmail.com

Received 18 July 2013; Accepted 7 October 2013

Academic Editor: Sebastian Feliu

Copyright (c) 2013 Rahul Bhola et al. This is an open access article distributed under the Creative Commons Attribution License, which permits unrestricted use, distribution, and reproduction in any medium, provided the original work is properly cited.

\begin{abstract}
The influence of a commonly used antibacterial mouth rinse, Listerine, on the corrosion behavior of one of the commonly used titanium alloys Ti6Al4V (two-phase structure, i.e., $\alpha$ and $\beta$ ) and a newer Ti15Mo (single $\beta$ phase) in normal saline solution has been investigated using electrochemical techniques. Interfacial electrochemical changes occurring at the oxide-solution interface have been analysed using EIS circuit modeling. Listerine acts as a corrosion inhibitor for Til5Mo alloy and a corrosion promoter for Ti6Al4V alloy.
\end{abstract}

\section{Introduction}

Listerine is a commonly used mouth rinse with antiplaque, anticaries, and antibacterial properties. It is used in several dental applications following periodontal procedures and routine oral prophylaxis. It was awarded the American Dental Association's seal of recognition in 1987 for its clinical efficacy in plaque control and gingival improvement [1].

Listerine antiseptic, developed by Warner-Lambert, was the first over-the-counter mouth rinse [2]. Listerine contains different essential oils, which are phenolics such as thymol, eucalyptol, menthol, and methyl salicylate and are known to retard plaque buildup and reduce gingivitis [310]. Thymol, eucalyptol, and menthol are known to possess proven antibacterial activity and are found in thyme (Thymus vulgaris), eucalyptus (Eucalyptus globulus), and peppermint (Mentha piperita), respectively. Methyl salicylate has antiinflammatory activity and is found in meadowsweet (Filipendula ulmaria) and willow (Salix spp.) [2]. The effect of Listerine on plaque was ascribed to its bactericidal properties related to the alteration of bacterial cell wall, which has been well documented in vitro and in vivo [11-15].
A newly inserted prosthesis and various surrounding tissues may get exposed to Listerine from minutes to days, depending upon the therapy performed and the local and systemic patient factors. It is thus important to understand the effect of Listerine on the electrochemical and corrosion behavior of titanium alloys in order to predict treatment prognosis. Cestarolli et al. [16] have compared the effect of mouthwashes including Listerine and a simulated body fluid on the corrosion behavior of an Fe-Cr-Ni alloy. The corrosion resistance of this alloy was the highest in the presence of Listerine mouthwash. However, the present study simulates the use of Listerine as an oral prophylactic rinse, in other words, the condition when the concentration of saliva gets altered due to the presence of Listerine in the mouth. The effect of this normal saline-Listerine solution has, thus, been explored on the behavior of titanium alloys when used as prostheses in patients. The conventional dental implants comprise the Ti6Al4V alloy but owing to its higher modulus of elasticity and thereby creating a greater modulus mismatch with the bone (stress shielding effect) newer beta alloys, Ti15Mo, with lower elastic modulus are being developed for use as implants in oral cavity. 


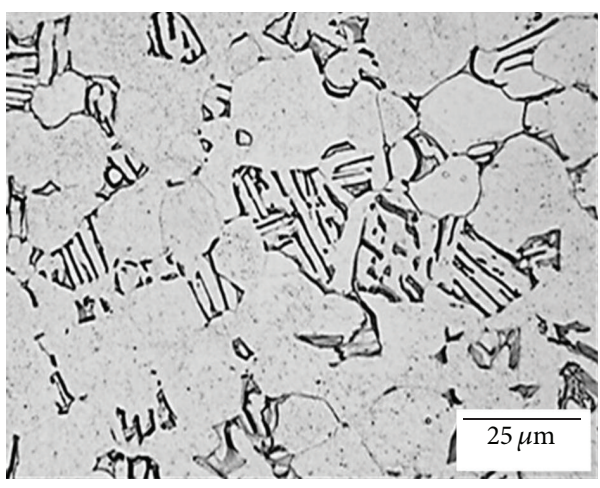

(a)

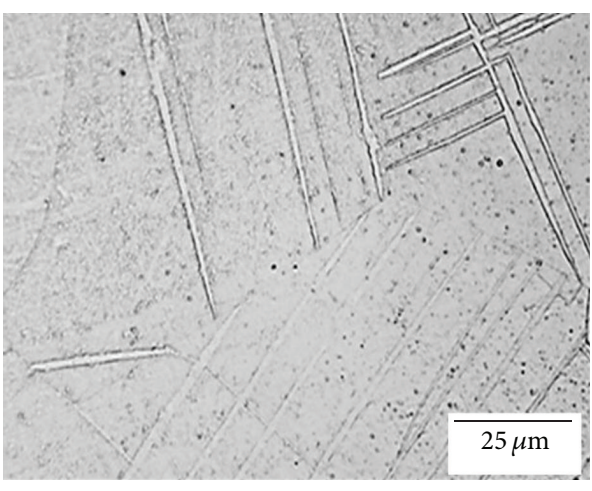

(b)

Figure 1: Microstructure of the titanium alloys: (a) Ti6Al4V, (b) Ti15Mo.

The aim of this investigation is to explore the influence of Listerine addition on the electrochemical behavior of Ti6Al4V (two phases structure, i.e., $\alpha$ and $\beta$ ) and Til5Mo (single $\beta$ phase) alloys in normal saline.

\section{Materials and Methods}

2.1. Materials Preparation. Titanium alloy samples Ti6Al4V (0.1\% C, $0.2 \% \mathrm{Fe}, 0.015 \% \mathrm{H}, 0.03 \% \mathrm{~N}, 0.2 \% \mathrm{O}, 6 \% \mathrm{Al}, 4 \%$ $\mathrm{V}$, and $89.45 \% \mathrm{Ti})$ and Til5Mo $(0.05 \% \mathrm{C}, 0.1 \% \mathrm{Fe}, 0.015 \%$ $\mathrm{H}, 0.01 \% \mathrm{~N}, 0.15 \% \mathrm{O}, 15 \% \mathrm{Mo}$, and $84.67 \% \mathrm{Ti}$ ) provided by ATI Wahchang (Albany, USA) were used for the present investigation. The specimens were finished with different grades of $\mathrm{SiC}$ grit papers up to 2400 grit, polished to a mirror finish, and finally degreased with acetone.

Normal saline solution (sodium chloride inj., USP, HOSPIRA; composition: $5.26 \mathrm{gL}^{-1}$ sodium chloride, $2.22 \mathrm{gL}^{-1}$ anhy. sodium acetate, $5.02 \mathrm{gL}^{-1}$ sodium gluconate, $0.37 \mathrm{gL}^{-1}$ potassium chloride, and $0.3 \mathrm{gL}^{-1}$ magnesium chloride hexahydrate) having $\mathrm{pH} 6.6$ was used to make two different concentrations of Listerine.

Listerine solution (LISTERINE, Johnson \& Johnson; composition: $0.092 \%$ eucalyptol, $0.042 \%$ menthol, $0.06 \%$ methyl salicylate, $0.064 \%$ thymol, $21.6 \%$ alcohol (ethanol), sorbitol, poloxamer 407, benzoic acid, zinc chloride, sucralose, sodium benzoate, and water) was used for the preparation of $25 \%$ and $50 \%$ solutions, respectively.

2.2. Microstructural Measurements. The metal specimens were degreased, dried, and mounted in bakelite resin. Mechanical grinding was done with $\mathrm{SiC}$ papers on a water cooled grinding stage. Polishing was performed using gradually decreasing sizes of diamond abrasive from $6 \mu \mathrm{m}$ to $1 \mu \mathrm{m}$ and finally using an alumina abrasive (with decreasing particle size from $0.50 \mu \mathrm{m}$ to $0.25 \mu \mathrm{m}$ ) and cold saturated hydrous oxalic acid suspension on a short circular velvet cloth. The specimens were washed in deionized water and ethanol and air-dried before etching. An etchant commonly known as the Kroll's reagent, a hydrous solution comprising $2 \mathrm{~mL} \mathrm{HF} \mathrm{(40 \%}$ conc.) and $6 \mathrm{~mL} \mathrm{HNO}_{3}$ (65\% conc.) in $100 \mathrm{~mL} \mathrm{H}_{2} \mathrm{O}$ (deionized), was used for etching. The microstructure obtained was determined using Olympus stereo microscope.
2.3. Electrochemical Measurements. A three-electrode cell assembly consisting of titanium alloy as the working electrode (WE), platinum wire as the counter electrode (CE), and a saturated calomel electrode as the reference electrode (RE) was used for the electrochemical measurements. Electrochemical testing was performed in a closed system at $298 \mathrm{~K}$ temperature under naturally aerated conditions using a PAR Potentiostat 273 A coupled to a PAR FRA 1255 using ZPlot/Corrware software. The sequence of electrochemical techniques has been described below.

Electrochemical Impedance Spectroscopy (EIS). Impedance measurements were performed at the open circuit potential (OCP) at 1 hour and 24 hours of immersion. The frequency sweep was applied from $10^{5}$ to $10^{-2} \mathrm{~Hz}$ with the AC amplitude of $10 \mathrm{mV}$.

Potentiodynamic Polarization. Potentiodynamic polarization measurements were performed at 24 hours of immersion by polarizing the working electrode from an initial potential of $-500 \mathrm{mV}$ versus OCP upto a final potential of $2 \mathrm{~V}$ versus RE. A scan rate of $1 \mathrm{mV} / \mathrm{s}$ was used for the polarization sweep.

\section{Results and Discussion}

The optical micrographs of annealed Ti6Al4V and Ti15Mo alloys are shown in Figure 1. The microstructure of Ti6Al4V alloy primarily consists of white large grains of the $\beta$ phase, which is primarily a body center cubic crystal structure (BCC), along with small volume fraction of $\alpha$ phase at the grain junctions, primarily hexagonal close pack structure (HCP). On the other hand, the microstructure of Til5Mo alloy primarily consists of large equiaxed grains of the $\beta$ phase (BCC) along with twin boundary.

The EIS data of Ti6Al4V and Ti15Mo alloys in normal saline solution in the absence and presence of Listerine was found to fit the equivalent circuit models shown in Figure 2, where $R_{s}$ is the solution resistance, $R_{\mathrm{ct}}$ is the charge transfer resistance, $W$ is the Warburg impedance due to diffusion, and $\mathrm{CPE}$ is the constant phase element for the capacitance of the passive oxide film. The impedance of the CPE is given by

$$
Z(\mathrm{CPE})=\left[Q(j \omega)^{n}\right]^{-1},
$$




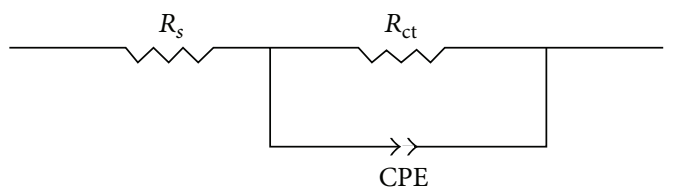

(a)

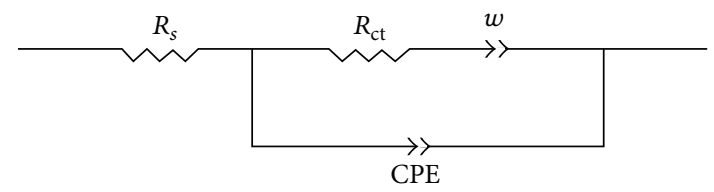

(b)

FIgUre 2: Circuit models used to fit EIS data for Ti6Al4V and Ti15Mo alloys.

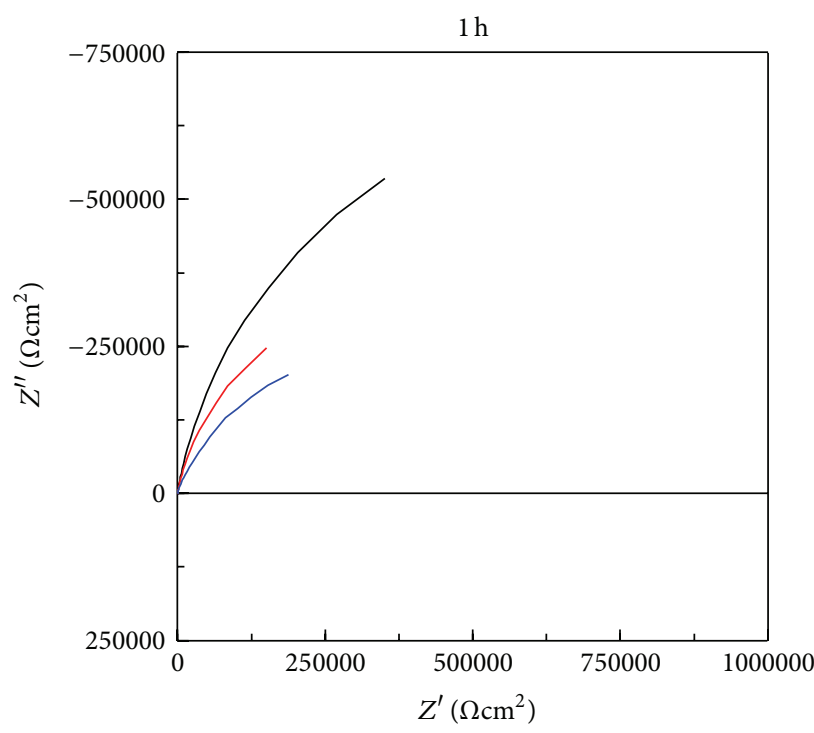

_ Ti64-normal saline

_ Ti64-normal saline $+50 \%$ Lis.

(a)

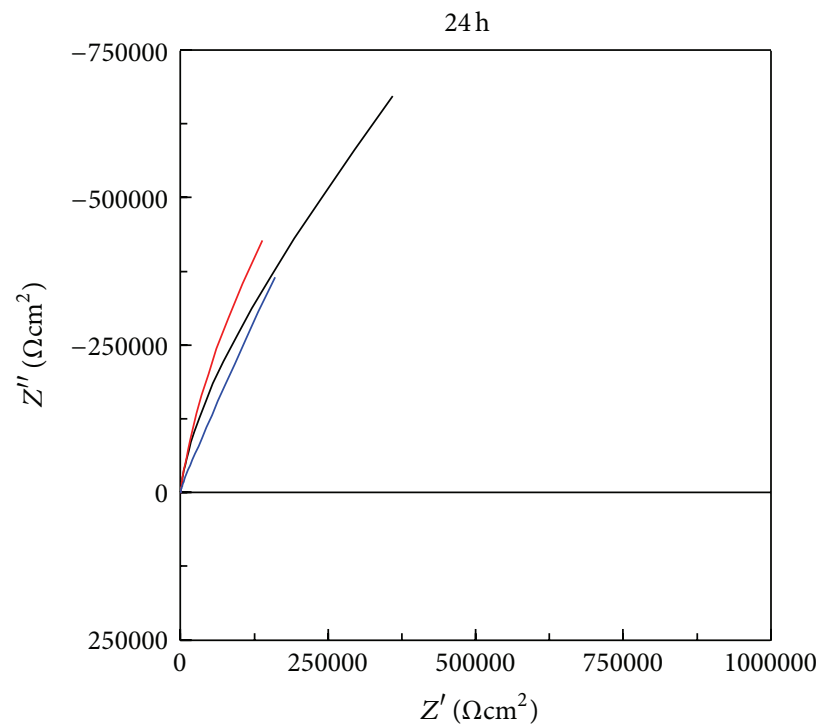

Ti64-normal saline

Ti64-normal saline $+25 \%$ Lis.

Ti64-normal saline + 50\% Lis.

(c)
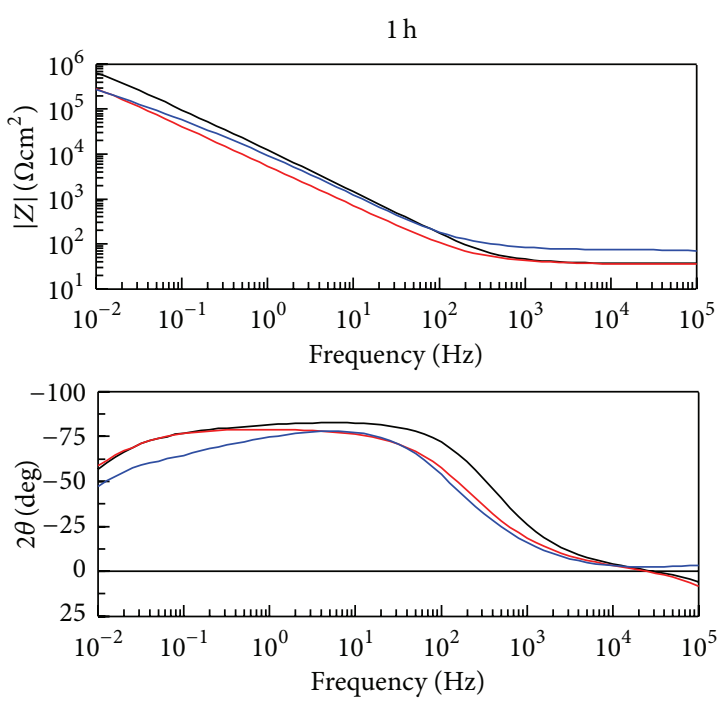

— Ti64-normal saline

Ti64-normal saline $+25 \%$ Lis.

_ Ti64-normal saline $+50 \%$ Lis.

(b)
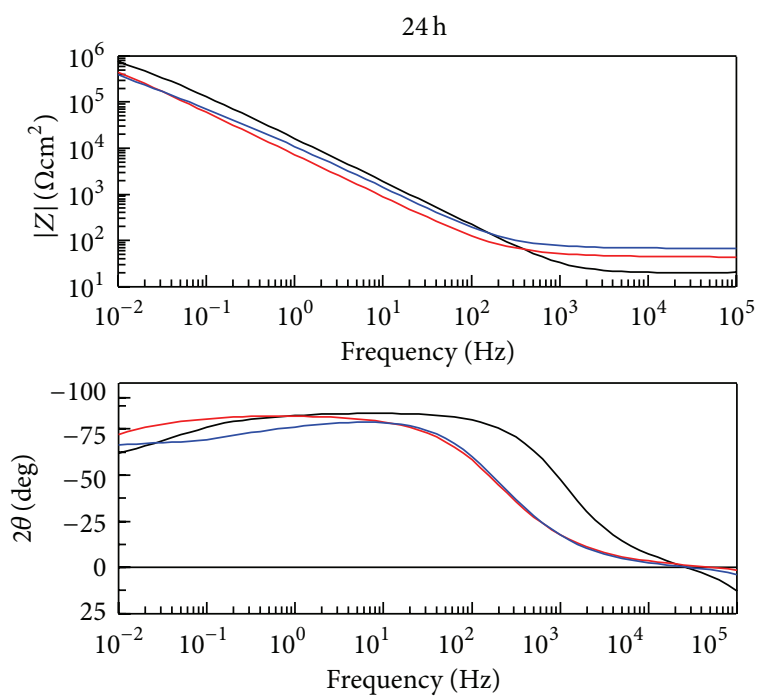

Ti64-normal saline

Ti64-normal saline $+25 \%$ Lis.

— Ti64-normal saline $+50 \%$ Lis

(d)

FIgURE 3: Impedance plots (Bode \& Nyquist) for Ti6Al4V alloy in normal saline solution in the absence and presence of $25 \%$ and $50 \%$ Listerine at $1 \mathrm{~h} \mathrm{((a)}$ and (b)) and $24 \mathrm{~h} \mathrm{((c)} \mathrm{and} \mathrm{(d))} \mathrm{of} \mathrm{immersion.}$ 
TABLE 1: EIS parameters for Ti6Al4V alloy in normal saline solution in the absence and presence of $25 \%$ and $50 \%$ Listerine at $1 \mathrm{~h}$ and $24 \mathrm{~h}$ of immersion.

\begin{tabular}{|c|c|c|c|c|}
\hline System & $R_{s}(\Omega \mathrm{cm})$ & $R_{\mathrm{ct}}\left(\Omega \mathrm{cm}^{2}\right)$ & $Q\left(\mathrm{~S} \mathrm{~cm}^{-2}\left(\mathrm{~s} \mathrm{rad}^{-1}\right)^{n}\right)$ & $n$ \\
\hline Normal saline $(1 \mathrm{~h})$ & 19.20 & $6.86 \times 10^{5}$ & $3.01 \times 10^{-5}$ & 0.919 \\
\hline Normal saline $+25 \%$ Lis. $(1 \mathrm{~h})$ & 19.24 & $4.13 \times 10^{5}$ & $7.00 \times 10^{-5}$ & 0.883 \\
\hline Normal saline $+50 \%$ Lis. $(1 \mathrm{~h})$ & 41.25 & $2.42 \times 10^{5}$ & $4.31 \times 10^{-5}$ & 0.854 \\
\hline Normal saline $(24 \mathrm{~h})$ & 10.10 & $2.68 \times 10^{5}$ & $2.27 \times 10^{-5}$ & 0.925 \\
\hline Normal saline $+25 \%$ Lis. $(24 \mathrm{~h})$ & 23.70 & $1.34 \times 10^{5}$ & $5.02 \times 10^{-5}$ & 0.906 \\
\hline Normal saline $+50 \%$ Lis. $(24 \mathrm{~h})$ & 37.51 & $6.38 \times 10^{5}$ & $3.69 \times 10^{-5}$ & 0.862 \\
\hline
\end{tabular}

where $Q$ is the constant of CPE, $\omega$ is the angular frequency in $\operatorname{rad} s^{-1}$, and $n$ is the exponential term which can vary between 1 for pure capacitance and 0 for a pure resistor [17]. $n$ is a measure of surface heterogeneity and the lower is its value, the higher is the surface roughening of the metal/alloy [18]. Diffusional impedance is characterized by three parameters: $W(R), W(T)$, and $W(P) . W(R)$ corresponds to the length of diffusion impedance, $W(T)$ is the diffusion time constant, and $W(P)$ is the phase factor $(0<W(P)<1)$.

Figure 3 shows the impedance plots for Ti6Al4V alloy and the corresponding impedance parameters evaluated from the circuit modeling have been listed in Table 1.

Ti6Al4V alloy fits the circuit model shown in Figure 2(a). The alloy exhibits the presence of a charge transfer electrochemical reaction in normal saline solution and also upon Listerine additions. At both 1 hour and 24 hours of immersion, both concentrations of Listerine show a decrease in the charge transfer resistance of the alloy, with the higher concentration producing a large decrease. The heterogeneity parameter, $n$, shows a decrease in the same order, implying that the surface becomes increasingly rough with increased additions of Listerine. These observations suggest that Listerine interferes with oxide growth in solution over the surface of Ti6Al4V alloy and rather brings about the dissolution of the oxide. In addition, the solution resistance has increased upon addition of Listerine to normal saline and the increase is higher for higher Listerine concentrations, which is due to the contribution from organic compounds present in Listerine.

Moreover, in each of these solutions, the charge transfer resistance has increased from 1 hour to 24 hours of immersion, even in the presence of Listerine. The increase in $R_{\mathrm{ct}}$ with immersion time is, however, less in case of $50 \%$ Listerine compared to the other two solutions.

Figure 4 shows the potentiodynamic polarization plots for Ti6Al4V alloy at 24 hours of immersion and the corresponding polarization parameters have been listed in Table 2 . It appears from the $I_{\text {corr }}$ values that $25 \%$ Listerine produces only a small increase in the corrosion rate compared to $50 \%$ Listerine. These results support the results obtained from EIS. The anodic current densities in the presence of Listerine do not differ much from normal saline solution near $E_{\text {corr }}$, but $50 \%$ Listerine shows an increase in cathodic current densities near $E_{\text {corr }}$, which causes a higher overall corrosion rate in the presence of $50 \%$ Listerine. The cathodic and anodic slopes have, however, not changed upon Listerine addition, which implies that the cathodic and anodic reaction mechanism occurring over the Ti6Al4V surface has not been altered.
TABLE 2: Polarization parameters for Ti6Al4V alloy in normal saline solution in the absence and presence of $25 \%$ and $50 \%$ Listerine.

\begin{tabular}{lcc}
\hline System & $E_{\text {corr }}(\mathrm{V}$ versus SCE $)$ & $I_{\text {corr }}\left(\mathrm{A} \mathrm{cm}^{-2}\right)$ \\
\hline Normal saline & -0.267 & $1.20 \times 10^{-8}$ \\
Normal saline $+25 \%$ Lis. & -0.343 & $1.67 \times 10^{-8}$ \\
Normal saline $+50 \%$ Lis. & -0.155 & $4.00 \times 10^{-8}$ \\
\hline
\end{tabular}

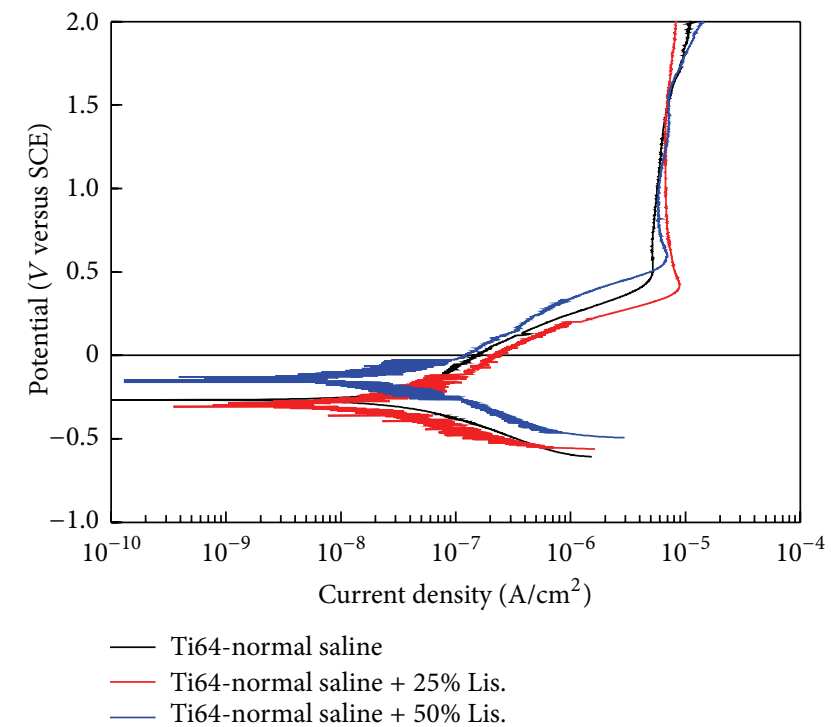

FIgUre 4: Potentiodynamic polarization plot for Ti6Al4V alloy in normal saline solution in the absence and presence of $25 \%$ and $50 \%$ Listerine at $24 \mathrm{~h}$ of immersion.

Figure 5 shows the impedance plots for Til5Mo alloy and the corresponding impedance parameters deduced from circuit modeling are given in Table 3.

Ti15Mo alloy in normal saline solution and in the presence of $25 \%$ Listerine shows the presence of charge transfer as well as mass transfer controlled electrochemical reactions at both 1 hour and 24 hours of immersion. However, in case of $50 \%$ Listerine containing solution, the alloy shows the presence of only a charge transfer reaction. At both immersion times, the charge transfer resistance increases in the presence of Listerine and the increase is more for the higher Listerine concentration. The overall polarization resistance of Ti15Mo alloy in the presence of Listerine is increased except for a decrease at 1 hour in the presence of $25 \%$ Listerine. In contrast to the overall trend at both 
TABLE 3: EIS parameters for Til5Mo alloy in normal saline solution in the absence and presence of $25 \%$ and $50 \%$ Listerine at $1 \mathrm{~h}$ and $24 \mathrm{~h}$ of immersion.

\begin{tabular}{lcccccccc}
\hline System & $R_{s}(\Omega \mathrm{cm})$ & $R_{\mathrm{ct}}\left(\Omega \mathrm{cm}^{2}\right)$ & $W(R)\left(\Omega \mathrm{cm}^{2}\right)$ & $W(P)$ & $W(T)(\mathrm{s})$ & $R_{p}\left(\Omega \mathrm{cm}^{2}\right)$ & $Q\left(\mathrm{~S} \mathrm{~cm}^{-2}\left(\mathrm{~s} \mathrm{rad}^{-1}\right)^{n}\right)$ & $n$ \\
\hline Normal saline (1 h) & 7.67 & $1.74 \times 10^{3}$ & $4.73 \times 10^{4}$ & 0.634 & 54.07 & $4.90 \times 10^{4}$ & $5.52 \times 10^{-5}$ & 0.898 \\
Normal saline + 25\% Lis. (1 h) & 20.63 & $1.87 \times 10^{3}$ & $3.74 \times 10^{4}$ & 0.619 & 59.20 & $3.92 \times 10^{4}$ & $1.0 \times 10^{-4}$ & 0.827 \\
Normal saline + 25\% Lis. (24 h) & 29.41 & $7.78 \times 10^{4}$ & - & - & - & $7.78 \times 10^{4}$ & $6.70 \times 10^{-5}$ & 0.895 \\
Normal saline (24h) & 9.23 & $1.37 \times 10^{3}$ & $4.02 \times 10^{4}$ & 0.632 & 53.32 & $4.16 \times 10^{4}$ & $4.97 \times 10^{-5}$ & 0.901 \\
Normal saline + 50\% Lis. (1 h) & 24.74 & $1.45 \times 10^{3}$ & $7.15 \times 10^{4}$ & 0.681 & 182.4 & $7.30 \times 10^{4}$ & $1.04 \times 10^{-4}$ & 0.824 \\
Normal saline + 50\% Lis. (24 h) & 30.12 & $1.11 \times 10^{5}$ & - & - & - & $1.11 \times 10^{5}$ & $6.49 \times 10^{-5}$ & 0.888 \\
\hline
\end{tabular}

$R_{p}$ is the polarization resistance of Ti15Mo alloy $\left(R_{\mathrm{ct}}+W(R)\right)$.

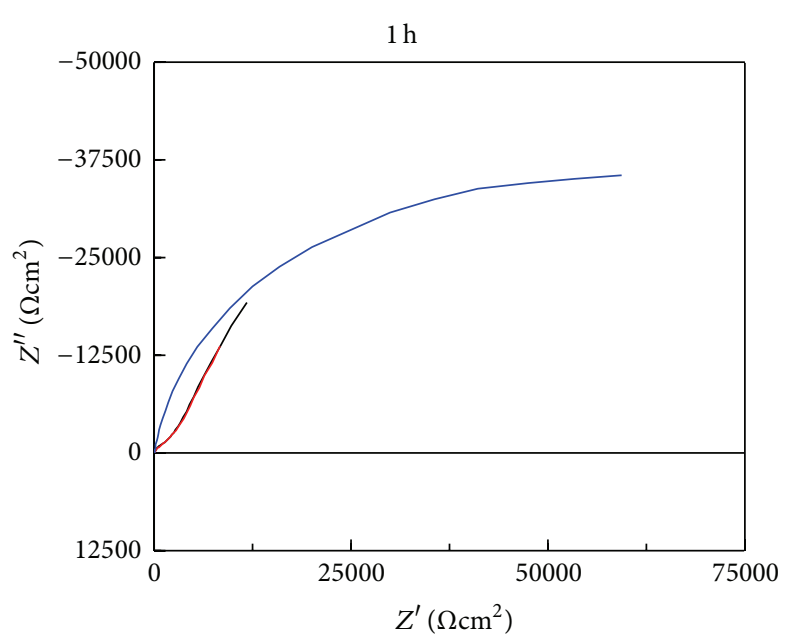

- Ti15Mo-normal saline
Ti15Mo-normal saline $+25 \%$ Lis

- Ti15Mo-normal saline $+50 \%$ Lis.

(a)

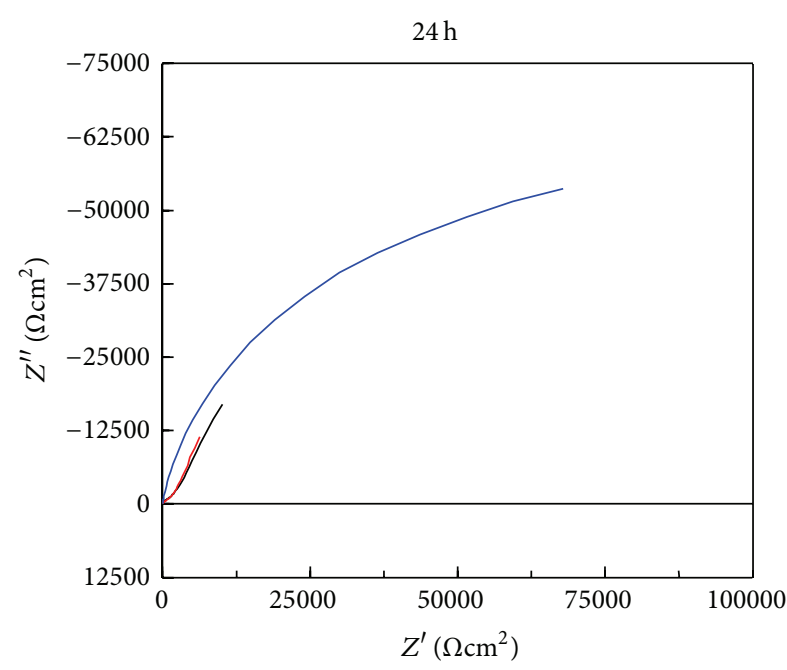

- Ti15Mo-normal saline

- Ti15Mo-normal saline $+25 \%$ Lis.

_ Ti15Mo-normal saline $+50 \%$ Lis.

(c)
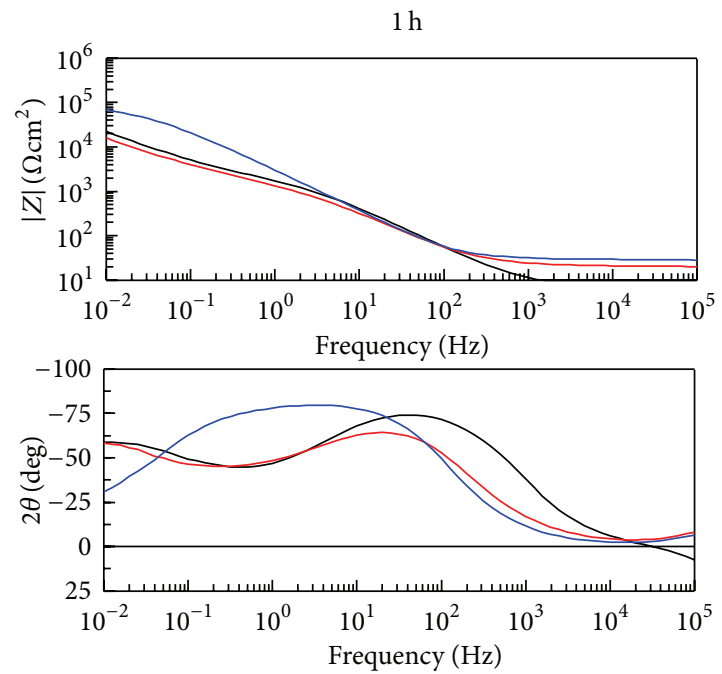

_ Ti15Mo-normal saline

_ Ti15Mo-normal saline $+25 \%$ Lis.

— Ti15Mo-normal saline $+50 \%$ Lis.

(b)
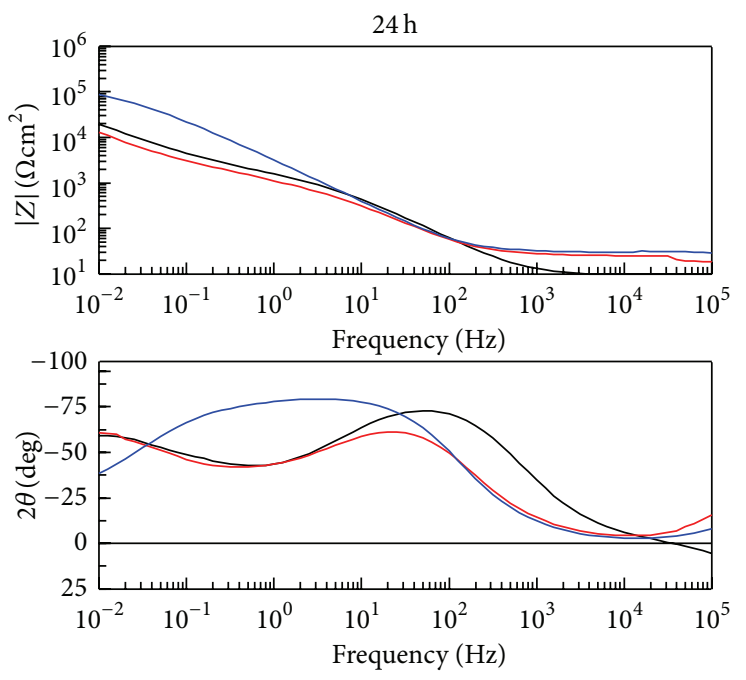

- Ti15Mo-normal saline

- Ti15Mo-normal saline $+25 \%$ Lis.

_ Ti15Mo-normal saline $+50 \%$ Lis.

FIGURE 5: Impedance plots (Bode \& Nyquist) for Ti15Mo alloy in normal saline solution in the absence and presence of $25 \%$ and $50 \%$ Listerine at $1 \mathrm{~h}((\mathrm{a})$ and $(\mathrm{b}))$ and $24 \mathrm{~h}((\mathrm{c})$ and $(\mathrm{d}))$ of immersion. 
TABLE 4: Polarization parameters for Ti15Mo alloy in normal saline solution in the absence and presence of $25 \%$ and $50 \%$ Listerine.

\begin{tabular}{lcc}
\hline System & $E_{\text {corr }}(\mathrm{V}$ versus SCE $)$ & $I_{\text {corr }}\left(\mathrm{A} \mathrm{cm}^{-2}\right)$ \\
\hline Normal saline & -0.402 & $5.82 \times 10^{-7}$ \\
Normal saline $+25 \%$ Lis. & -0.222 & $4.06 \times 10^{-7}$ \\
Normal saline $+50 \%$ Lis. & -0.168 & $3.43 \times 10^{-7}$ \\
\hline
\end{tabular}

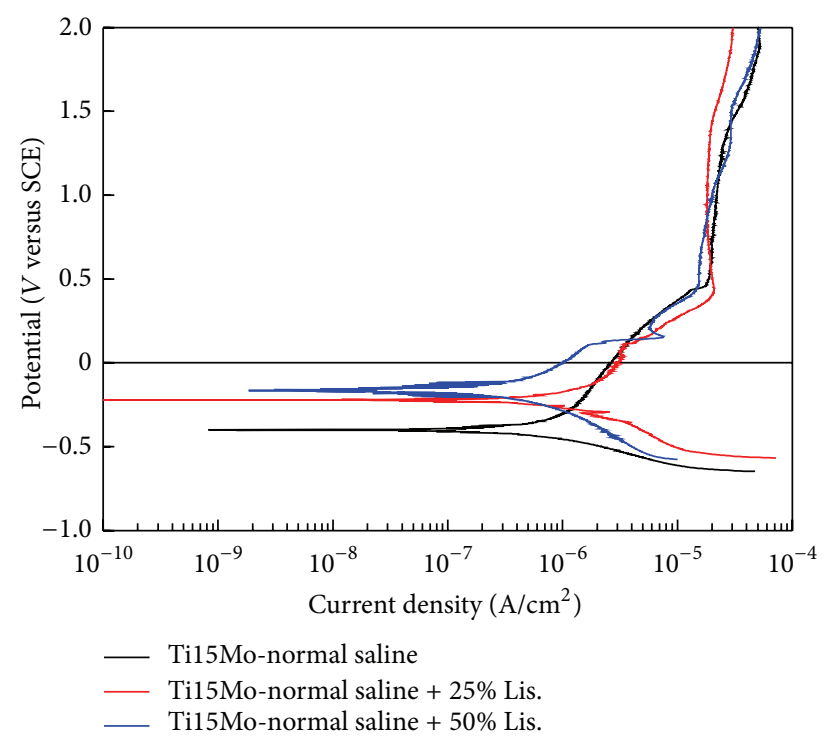

Figure 6: Potentiodynamic polarization plot for Ti15Mo alloy in normal saline solution in the absence and presence of $25 \%$ and $50 \%$ Listerine at $24 \mathrm{~h}$ of immersion.

immersion hours for both concentrations, this observation can be ignored.

With the increase in immersion time from 1 hour to 24 hours, the overall polarization resistance of Ti15Mo alloy decreases in normal saline, but in the presence of both Listerine concentrations, it shows an increase with time.

These results show that the corrosion resistance of Ti15Mo alloy is improved upon Listerine addition in normal saline solution. In other words, Listerine acts as a corrosion inhibitor for Til5Mo alloy under these conditions.

Figure 6 illustrates the potentiodynamic polarization curves for Ti15Mo alloy at 24 hours of immersion and the corresponding polarization parameters have been given in Table 4 . The $I_{\text {corr }}$ values have decreased in the presence of Listerine which suggests the corrosion inhibition of Ti15Mo alloy by Listerine in normal saline solution. Furthermore, the polarization plots for Ti15Mo alloy illustrate a change in cathodic and anodic slopes upon Listerine addition to normal saline solution which indicates that Listerine alters the reaction mechanism of the cathodic and anodic reactions occurring on the Til5Mo surface by adsorption or blocking of the active sites on the alloy surface. It is possible that the corrosion inhibition effect of Listerine for Ti15Mo alloy is due to the influence of the organic compounds present in Listerine such as sodium benzoate, benzoic acid, methyl salicylate, sorbitol, menthol, and thymol, which are known for their inhibition action [19-24]. On the contrary, Ti6Al4V alloy investigated in this study has shown higher corrosion rates in the presence of Listerine. Corrosion is a property of the system which includes both the material under investigation and its environment. Corrosivity of an environment will depend upon the material and the corrodibility of a material will depend upon the environment. Though Ti15Mo alloy shows a higher corrosion rate over the Ti6Al4V alloy, its corrosion rate $\left(\sim 5 \times 10^{-3} \mathrm{mpy}\right)$ belongs to the outstanding corrosion resistance category as classified by Fontana [25] and is less likely to be detrimental to the host tissue. Moreover, being a $\beta$-alloy, it has a lower modulus mismatch with bone compared to the mixed Ti6Al4V alloy and remains a better choice for use as an implant.

\section{Conclusions}

Antiplaque and antimicrobial action of Listerine is well acknowledged in the clinical community. The titanium alloys investigated in normal saline solution in this study, Ti6Al4V ( $\alpha$ and $\beta$ phases) and Til5Mo ( $\beta$ phase), exhibit variable corrosion behavior in the presence of Listerine, with Ti6Al4V alloy showing an increase in corrosion rate and Til5Mo showing a decrease in corrosion rate upon Listerine addition.

Appropriate care must hence be taken during alloy selection for prosthetic applications in a specific clinical situation as the increased corrosion and release of byproducts into the surrounding tissues in the presence of antibacterial mouthwashes under certain conditions could be detrimental and bring about a mild to severe adverse reaction which may finally lead to treatment failure.

A corrosion inhibitor could be used additionally to prevent dissolution of the prosthesis in the presence of mouthwashes causing corrosion of alloys.

\section{References}

[1] W. C. Waggoner, Clinical Safety and Efficacy Testing of Cosmetics, vol. 8 of Cosmetic science and technology series, Marcel Dekker, New York, NY, USA, 1990.

[2] L. A. Cindy, The Antibiotic Alternative: The Natural Guide to Fighting Infection and Maintaining a healthy Immune System, Healing Arts Press, 2000.

[3] J. Fornell, Y. Sundin, and J. Lindhe, "Effect of Listerine on dental plaque and gingivitis," Scandinavian Journal of Dental Research, vol. 83, no. 1, pp. 18-25, 1975.

[4] J. M. Gordon, I. B. Lamster, and M. C. Seiger, "Efficacy of listerine antiseptic in inhibiting the development of plaque and gingivitis," Journal of Clinical Periodontology, vol. 12, no. 8, pp. 697-704, 1985.

[5] P. Axelsson and J. Lindhe, "Efficacy of mouthrinses in inhibiting dental plaque and gingivitis in man," Journal of Clinical Periodontology, vol. 14, no. 4, pp. 205-212, 1987.

[6] S. Mankodi, N. M. Ross, and K. Mostler, "Clinical efficacy of listerine in inhibiting and reducing plaque and experimental gingivitis," Journal of Clinical Periodontology, vol. 14, no. 5, pp. 285-288, 1989.

[7] L. G. DePaola, C. D. Overholser, T. F. Meiller, G. E. Minah, and C. Niehaus, "Chemotherapeutic inhibition of supragingival 
dental plaque and gingivitis development," Journal of Clinical Periodontology, vol. 16, no. 5, pp. 311-315, 1989.

[8] C. D. Overholser, T. F. Meiller, L. G. DePaola, G. E. Minah, and C. Niehaus, "Comparative effects of 2 chemotherapeutic mouthrinses on the development of supragingival dental plaque and gingivitis," Journal of Clinical Periodontology, vol. 17, no. 8, pp. 575-579, 1990.

[9] N. M. Ross, S. M. Mankodi, S. M. Mostler, C. H. Charles, and L. L. Bartels, "Effect of rinsing time on antiplaque-antigingivitis efficacy of listerine," Journal of Clinical Periodontology, vol. 20, no. 4, pp. 279-281, 1993.

[10] M. Brecx, E. Brownstone, L. MacDonald, S. Gelskey, and M. Cheang, "Efficacy of Listerine, Meridol and chlorhexidine mouthrinses as supplements to regular tooth-cleaning measures," Journal of Clinical Periodontology, vol. 19, no. 3, pp. 202207, 1992.

[11] J. Swarbrick and J. C. Boylan, Encyclopedia of Pharmaceutical Technology, vol. 2, Marcel Dekker, New York, NY, USA, 2002.

[12] N. M. Ross, C. H. Charles, and S. S. Dills, "Long-term effects of listerine antiseptic on dental plaque and gingivitis," Journal of Clinical Dentistry, vol. 1, no. 4, pp. 92-95, 1989.

[13] S. Jenkins, M. Addy, W. Wade, and R. G. Newcombe, “The magnitude and duration of the effects of some mouthrinse products on salivary bacterial counts," Journal of clinical periodontology, vol. 21, no. 6, pp. 397-401, 1994.

[14] L. G. DePaola, G. E. Minah, C. Daniel Overiiolser et al., "Effect of an antiseptic mouthrinse on salivary microbiota," The American Journal of Dentistry, vol. 9, no. 3, pp. 93-95, 1996.

[15] P. Pan, M. L. Barnett, J. Coelho, C. Brogdon, and M. B. Finnegan, "Determination of the in situ bactericidal activity of an essential oil mouthrinse using a vital stain method," Journal of Clinical Periodontology, vol. 27, no. 4, pp. 256-261, 2000.

[16] D. T. Cestarolli, V. A. Alves, and L. A. Da Silva, "In situ and ex situ characterization of a Fe-Cr-Ni alloy in mouthwashes and Hank's solution," Chemical Papers, vol. 62, no. 3, pp. 326-328, 2008.

[17] C. H. Hsu and F. Mansfeld, "Concernng the conversion of the constant phase element parameter Y0 into a capacitance," Corrosion, vol. 57, no. 9, pp. 747-748, 2001.

[18] S. Chongdar, G. Gunasekaran, and P. Kumar, "Corrosion inhibition of mild steel by aerobic biofilm," Electrochimica Acta, vol. 50, no. 24, pp. 4655-4665, 2005.

[19] P. Agarwal and D. Landolt, "Effect of anions on the efficiency of aromatic carboxylic acid corrosion inhibitors in near neutral media: experimental investigation and theoretical modeling," Corrosion Science, vol. 40, no. 4-5, pp. 673-691, 1998.

[20] F. Mansfeld, Corrosion Mechanisms, vol. 139, Marcel Dekker, New York, NY, USA, 1987.

[21] P. Premkumar, K. Kannan, and M. Natesan, "Evaluation of menthol as vapor phase corrosion inhibitor for mild steel in $\mathrm{NaCl}$ environment," Arabian Journal for Science and Engineering, vol. 34, no. 2, pp. 71-79, 2009.

[22] L. J. Aljinović and V. Gotovac, "Adsorption and corrosion inhibition properties of thymol," Journal of Applied Electrochemistry, vol. 15, no. 5, pp. 767-770, 1985.

[23] R. K. Dinnappa and S. M. Mayanna, "Benzoic acid and substituted benzoic acids as interfacial corrosion inhibitors for copper in $\mathrm{HClO}_{4}$," Journal of Applied Electrochemistry, vol. 11, no. 1, pp. 111-116, 1981.

[24] R. T. Ignash, I. E. Zarinya, and B. A. Berge, "Synthesis and study of polyol borates as corrosion inhibitors for steel and nonferrous metals," Russian Journal of Applied Chemistry, vol. 82, no. 12, pp. 2146-2150, 2009.

[25] M. G. Fontana, Corrosion Engineering, McGraw-Hill, New York, NY, USA, 3rd edition, 1986. 

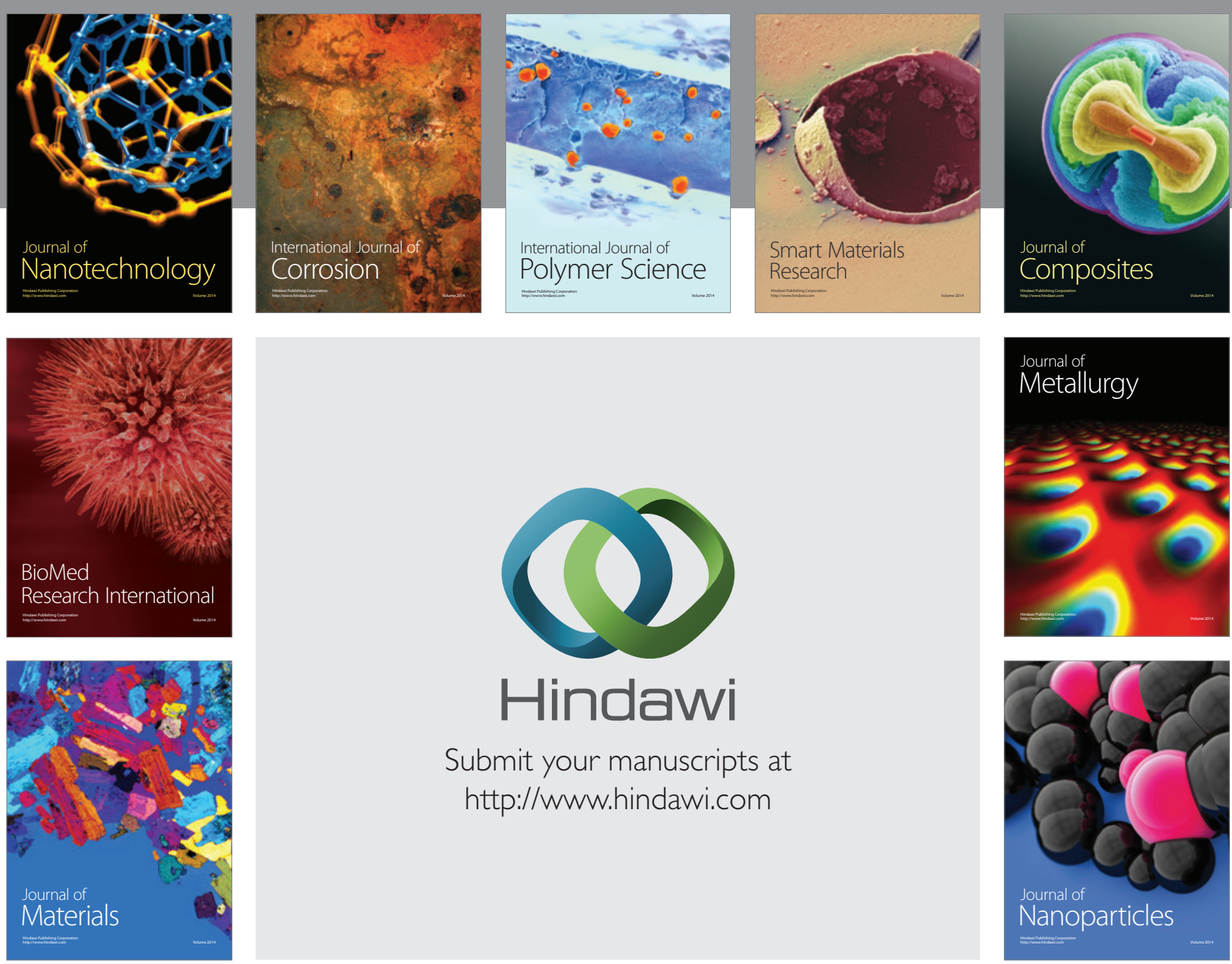

Submit your manuscripts at http://www.hindawi.com
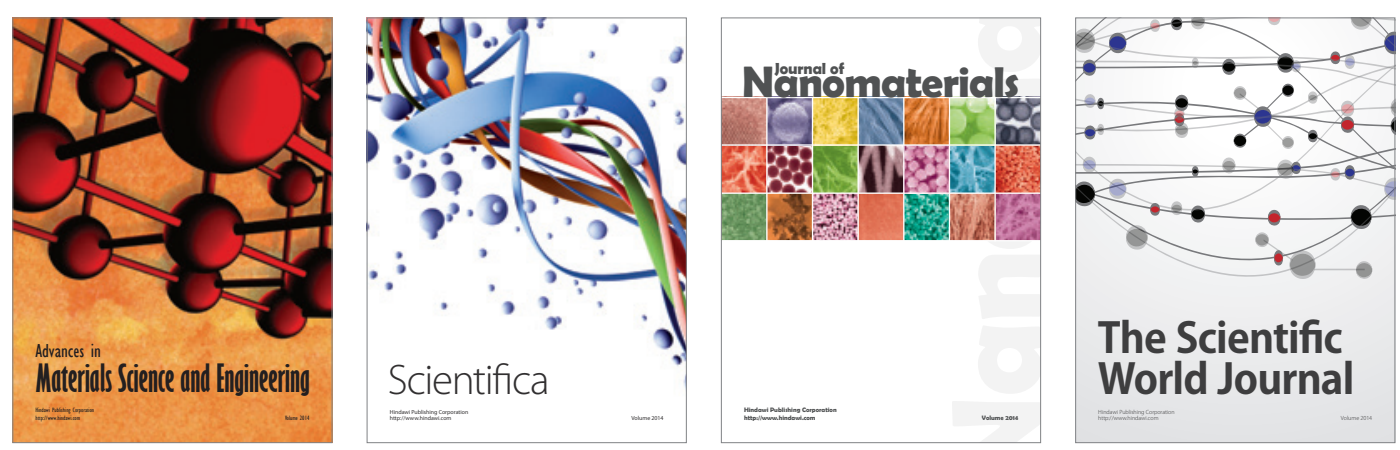

\section{The Scientific World Journal}
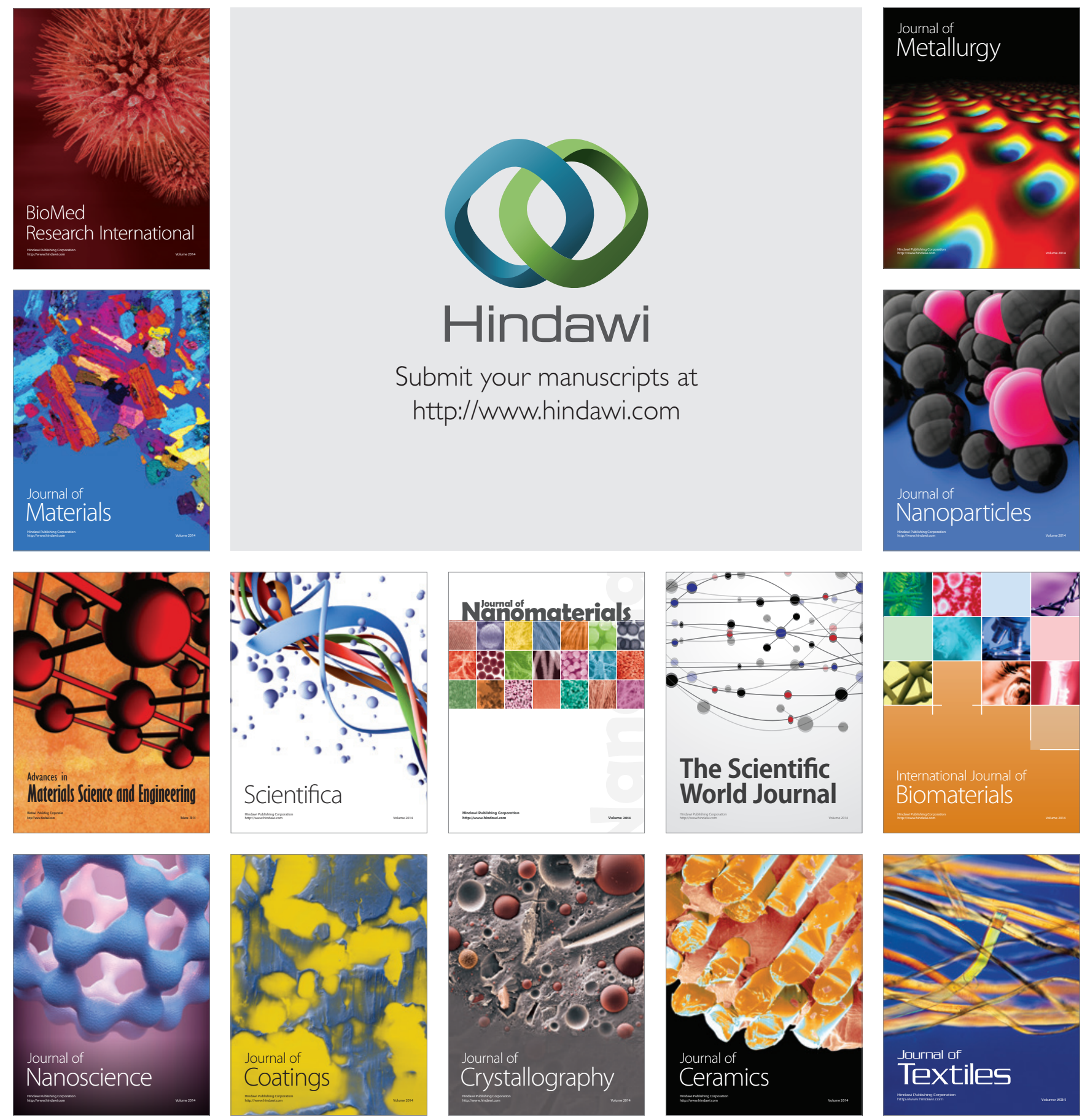